\title{
Características de repositório educacional aberto para usuários de língua brasileira de sinais
}

\author{
Open educational repository features for \\ Brazilian sign language users
}

Romario Antunes da SILVA'

Rosângela Schwarz RODRIGUES²

\section{Resumo}

O objetivo desse artigo é identificar as características que um repositório educacional aberto deve apresentar para atender as necessidade de informação dos alunos surdos e ouvintes do curso Letras Libras na modalidade a distância da Universidade Federal de Santa Catarina. Os objetivos específicos foram: a) descrever o perfil dos alunos surdos e ouvintes; b) examinar o uso das tecnologias da informação por esses alunos; e c) identificar os documentos que um repositório deve apresentar para atender as necessidades de informação desses alunos. A pesquisa é exploratória, descritiva e qualitativo-quantitativa, e a análise foi realizada com estatística descritiva e análise de conteúdo. Conclui-se que os alunos utilizam o e-mail, as listas de discussão, o Messenger, ferramentas para compartilhamento de vídeos e os sites para surdos. Os alunos consideram muito importantes os processadores de texto, Messenger, Movie Maker, Media Player e planilhas para cálculo. Os alunos surdos consideram como documentos mais relevantes as videoaulas, dicionários e apostilas, e os alunos ouvintes, as videoaulas, os livros e as apostilas. O tipo de conteúdo requisitado são notícias sobre surdos, língua brasileira de sinais, tradução, tecnologia, linguística, aprendizagem do português, interpretação médico-jurídica e cultura surda. Os suportes requisitados para acesso à informação são os dicionários, vídeos, livros digitais e artigos. Os alunos preferem acessar as informações no repositório por meio de língua de sinais, legendas e em português.

Palavras-chave: Acesso livre. Língua brasileira de sinais. Repositório educacional. Surdo.

\begin{abstract}
The research aims to identify the characteristics that an open educational repository should have in order to meet the information needs of deafstudents and those able to hear, participating in the Languages and Brazilian sign language course in distance education mode from Universidade Federal de Santa Catarina. The specific objectives were: a) describing the profile of the deaf and those able to hear; b) analyzing the use of information technology by students; and c) identifying documents that a repository should provide to meet the information needs of students. This work is classified as an investigative and descriptive study with a qualitative and quantitative approach, and analysis was performed with descriptive statistics and content analysis. In order to achieve the proposed objectives a questionnaire was applied to 98 students - deaf and able to hear participating in the Languages and Libras course. It was concluded that students use e-mail, discussion lists, Messenger, video sharing tools, and sites for deaf people. Students consider word processors, Messenger, Movie Maker, Media Player, and spreadsheets to be very important. Deafstudents consider video-lessons, dictionaries and booklets; and students able to hear considervideo-lessons, books and booklets to be the most important documents. News about deafpeople, Brazilian sign language, translation, technology, linguistics, Portuguese learning, medical-legal interpretation and deaf culture are main topics requested by the students. Dictionaries, videos, digital books and articles are means requested by the students for accessing the information. Students prefer to have access to the information in the repository using the sign language, subtitles and in Portuguese.
\end{abstract}

Keywords: Free access. Brazilian sign language. Educational repository. Deaf people.

1 Bibliotecário, Florianópolis, SC, Brasil.

2 Professora Doutora, Universidade Federal de Santa Catarina, Programa de Pós-Graduação em Ciência da Informação. Campus Universitário, Trindade, 88045-000, Florianópolis, SC, Brasil. Correspondência para/Correspondence to: R.S. RODRIGUES. E-mail: <rosangela@cin.ufsc.br>.

Recebido em 19/4/2012, reapresentado em 12/9/2012 e aceito para publicação em 27/9/2012. 


\section{Introdução}

Um dos desafios da sociedade atual é permitir que a evolução tecnológica ocorra em consonância para todos os indivíduos independentemente de seu nível econômico, social ou cultural. A implantação de políticas que tenham como objetivo ampliar a capacidade de inovação, proteger a diversidade cultural e estimular o desenvolvimento local são requisitos essenciais para promover não apenas a inclusão, mas principalmente a afirmação social dos diferentes níveis da sociedade e territórios no cenário de transformação (Albagli, 2006).

O reconhecimento das diferenças culturais e das características que compõem os diversos estratos que formam a sociedade representa um ponto importante para a promoção da inclusão, reduzindo as diferenças entre os indivíduos. Os surdos, que criaram associações em diversos países, e, no Brasil, obtiveram, em 2002, a aprovação da lei da Língua Brasileira de Sinais (Libras), que a reconhece como um meio legal de comunicação e expressão, o que contribuiu para seu acesso às universidades. As Tecnologias de Informação e Comunicação (TIC) são fatores que têm contribuído para que os surdos sejam integrados à sociedade, facilitando o acesso à educação, à saúde e ao lazer, entre outros direitos.

Os movimentos de acesso livre à informação que eclodiram em vários países do mundo divulgam o livre acesso à informação científica e podem contribuir para o acesso à informação aos surdos. No que se refere ao ensino, ocorreram transformações importantes na maneira como os materiais educacionais são projetados, disponibilizados e entregues às pessoas que desejam aprender (Silva et al., 2010). Isso se deve em parte ao uso crescente da Internet em atividades de ensino e ao acesso rápido ao grande número de materiais disponibilizados online. Segundo Rodrigues et al. (2011), as iniciativas de Recursos Educacionais Abertos podem abranger cursos e conteúdos abertos, ferramentas de software livre, materiais abertos para aprendizagem eletrônica construídos por docentes, repositórios de objetos de aprendizagem e cursos completos.

A visão sociocultural da surdez considera os aspectos sociais, linguísticos e culturais do surdo. Com isso, a surdez não é identificada pelos seus aspectos negativos e sim como uma característica do indivíduo que utiliza uma língua visuoespacial, como recurso essencial para a sua inclusão.

O termo "surdo" é apropriado, pois, conforme Sá (2002, p.49), "Está mais condizente com a visão sociocultural da surdez". A "diferença" prevalece sobre a "deficiência", pois, "é na diferença que se baseia a essência psicossocial da surdez". A experiência visual compensa, pelo menos em parte, a falta de audição, proporcionando novas habilidades que permitem ao surdo a comunicação e compreensão dos conteúdos necessários para sua formação cognitiva.

Uma das formas de comunicação dos surdos ocorre por meio da língua de sinais, e, sob o ponto de vista linguístico, é considerada um idioma, pois apresenta em sua estrutura aspectos fonológicos, morfológicos, sintáticos, semânticos e pragmáticos.

A Libras é formada pelos parâmetros fonológicos propostos por Stokoe (1960), que, de acordo com Quadros e Karnopp (2004), são classificados em locação ou ponto de articulação (L), movimento (M) e configuração de mão (CM) e orientação da palma da mão. O uso dos parâmetros desenvolvidos por Stokoe (1960) representa a estrutura básica da língua de sinais.

A configuração de mão diz respeito à sua forma na realização dos sinais: o movimento pode ou não estar presente num sinal e refere-se a um grande número de formas e direções para sua articulação. A locação ou ponto de articulação é o lugar em frente ao corpo onde o sinal é articulado, e a orientação de mão é a direção que a palma da mão aponta na realização do sinal (Brito, 1995; Quadros; Karnopp, 2004; Gesser, 2009).

A forma escrita da língua de sinais é representada por meio do sistema signwriting. Essa forma de escrita foi criada por Valerie Sutton em 1974 e expressa os movimentos, as formas das mãos, as marcas não manuais e os pontos de articulação do sinal.

Este trabalho tem como objetivo geral identificar as características que um repositório educacional aberto deve apresentar para atender as necessidade de informação dos alunos surdos e ouvintes do curso Letras Libras na modalidade a distância (EaD) da Universidade Federal de Santa Catarina (UFSC). Os objetivos específicos são: a) descrever o perfil dos alunos surdos e ouvintes do curso Letras Libras-EaD; b) examinar o uso das tecnologias 
da informação pelos alunos surdos e ouvintes do curso Letras Libras-EaD, e c) identificar os documentos que um repositório deve apresentar para atender às necessidades de informação dos alunos surdos e ouvintes do curso Letras Libras-EaD.

\section{Recursos educacionais abertos}

Os Recursos Educacionais Abertos (REA) são materiais em formato digital compartilhados livremente por professores, alunos e autodidatas com o objetivo de serem utilizados e reutilizados para o ensino, aprendizagem e pesquisa. Esses recursos podem ser conteúdos educativos, softwares em desenvolvimento, uso e distribuição livre do conteúdo e a implementação de recursos como as licenças abertas (Organisation for Economic Co-Operation and Development, 2008). Os REA também podem incluir mapas, currículos, materiais didáticos, vídeos, aplicativos multimídia e qualquer tipo de material que foi desevolvido para uso no ensino e na aprendizagem e que seja disponibilizado livremente sem a cobrança de royalties ou taxas de licença (Butcher, 2011).

O uso de Recursos Educacionais Abertos tem se intensificado com o aumento da demanda na educação a distância em diversos países. É visível que, a cada ano, em decorrência da implementação de novas tecnologias, modelos e metodologias de cursos, desenvolvimento de recursos técnicos e formação de capital humano, a oferta de recursos educacionais tenha aumentado (Laaser et al., 2009). Esses conteúdos podem ser compartilhados pelas instituições seguindo padrões e normas que facilitam a migração dos dados, permitindo a interoperabilidade.

O conceito de Recursos Educacionais Abertos está fundamentado na ideia de reutilização de materiais criados por alguém em alguma parte do mundo (Organisation for Economic Co-Operation and Development, 2008). Por meio de sistemas interoperáveis com a utilização de normas e padrões, os recursos podem ser utilizados livremente e mesmo assim garantem a propriedade intelectual de quem o desenvolveu por meio da licença Creative Commons, licença que surgiu com o objetivo de disponibilizar à comunidade internacional a informação científica, sem as restrições habituais em relação aos direitos de autor. O compartilhamento dos recursos educacionais abertos tem ocorrido por inúmeras razões tecnológicas, econômicas, sociais e jurídicas.
Uma barreira técnica é a falta de disponibilidade de banda larga. A falta de recursos para investir em hardware e software a fim de desenvolver e compartilhar REA é uma barreira econômica. Se menciona tais barreiras como obstáculos significativos nos países em desenvolvimento. As barreiras sociais incluem a falta de habilidades para usar inovações técnicas e os obstáculos culturais para compartilhar e empregar os recursos desenvolvidos por mais professores e instituições. Os marcos jurídicos são novos planos de propriedade intelectual que facilitam o repasse livre e a reutilização de conteúdo. Os marcos sociais incluem um desejo mais forte de compartilhar (Organisation for Economic Co-Operation and Development, 2008, p.15).

Ao superar as barreiras tecnológicas, econômicas, sociais e jurídicas, percebe-se que os REA representam instrumentos a serem utilizados na educação, e que, ao serem compartilhados entre os educadores, validam sua importância no processo de ensino, em especial no ensino a distância.

\section{Repositórios digitais}

Os repositórios digitais surgiram com a difusão do "Movimento Acesso Aberto", que foi uma resposta aos altos preços cobrados para acesso às revistas científicas. Os repositórios digitais podem armazenar e disponibilizar diversos tipos de objetos e recursos educacionais abertos e em formato digital e geralmente estão vinculados a uma instituição ou a uma área do conhecimento.

Os objetos e Recursos Educacionais Abertos podem ser mais facilmente recuperados se forem adotados critérios de interoperabilidade. Uma das principais razões na adoção de critérios de interoperabilidade dos repositórios é facilitar a recuperação da informação. Como descrevem Café et al. (2003), o conteúdo de cada repositório poderá compor um arquivo global de uma área do conhecimento. Dessa forma, a informação é acessada com facilidade e gratuitamente, o que permite que o conteúdo das pesquisas se torne mais visível.

O autoarquivamento é mais um elemento identificado nos repositórios que fomenta a disseminação da informação científica, por meio do qual o próprio autor disponibiliza seu artigo para acesso aberto (Triska; Café, 2001; Moreno et al., 2006). Pelo uso do autoarquivamento, 
a informação fica disponível para o leitor rapidamente, pois não segue os métodos tradicionais de publicação empregados pelas editoras dos artigos científicos. Os repositórios apresentam características específicas que os diferenciam das bibliotecas digitais ou de outras formas de publicações eletrônicas.

Seus sites apresentam facilidades que permitem a um autor submeter diretamente seus trabalhos, armazená-los em forma digital permanentemente, editá-los, substituí-los e receber críticas e contribuições; ao submeter um trabalho para armazená-lo e disponibilizá-lo no arquivo eletrônico, um autor também o descreve em formulário de catalogação, de onde serão extraídos os metadados como autor, título, idioma, assunto etc. que permitirão recuperar o documento; os metadados são, portanto, obtidos como um subproduto da submissão de um documento (Marcondes; Sayão, 2002, p.46).

A participação direta do autor no processo de armazenamento e edição dos arquivos dá aos repositórios maior dinamismo no processo. O sucesso na recuperação da informação disponível nos repositórios depende da precisão dos metadados extraídos pelos autores nos arquivos digitais. Quanto mais detalhada for a indexação dos metadados mais facilmente o documento será recuperado.

Os repositórios de acesso livre podem ser localizados no Diretório de Repositórios de Acesso Aberto (OpenDOAR). A busca para a localização dos repositórios pode ser realizada pelo tipo de arquivo disponível no repositório, área do conhecimento, país onde o repositório foi desenvolvido, idioma predominante e software utilizado pelo sistema.

A partir do acesso ao banco de dados disponível no diretório, é possível verificar o crescimento do número de repositórios em âmbito mundial. Nesse diretório, estão disponíveis apenas os repositórios que seguem a política do acesso aberto à informação. Após a localização do repositório por meio dos termos de busca, tem-se acesso ao repositório por meio de um link e a uma descrição resumida com informações sobre a organização que o disponibiliza, software utilizado, número de arquivos disponíveis para download, áreas do conhecimento, tipo de conteúdo ofertado, idioma e políticas de acesso.

O diretório também disponibiliza um número relevante de dados estatísticos sobre os repositórios distribuídos em nível mundial. Esses dados confirmam os tipos de conteúdos dos repositórios, organizações responsáveis, distribuição por países, idiomas, entre outros. Com essas informações, é possível verificar o crescimento do número de repositórios e sua distribuição, analisar os tipos de arquivos que o compõem (artigos, livros, teses, objetos de aprendizagem, patentes, referências, multimeios e softwares).

O crescimento do número de repositórios reflete sua aceitação pela comunidade científica, inicialmente nas áreas exatas e naturais, como mais uma ferramenta para a divulgação da informação no meio acadêmico.

Os repositórios podem ser classificados em temáticos e institucionais. Os temáticos estão relacionados a uma determinada área do conhecimento. Conforme Fachin et al. (2009, p.222), "Eles apresentam a produção intelectual de determinada área do conhecimento". Esse tipo de repositório não necessita estar vinculado a uma instituição específica para ser reconhecido.

Os repositórios institucionais, na visão de Café et al. (2003), evoluíram a partir do agrupamento dos repositórios temáticos e estão sob a responsabilidade de uma instituição. Têm a função de armazenar, organizar e disseminar os arquivos vinculados à instituição. Para McLendon (2005), os repositórios institucionais armazenam e fornecem acesso aos documentos produzidos pela instituição, servindo com uma alternativa diante dos altos custos das publicações tradicionais e contribuindo para o prestígio da instituição. Quanto maior for o alcance dos repositórios maior será seu reconhecimento, o que requer a adoção de políticas que facilitem seu acesso e uso.

A utilização dos repositórios institucionais potencializa a troca de informações pela comunidade científica (Fachin et al., 2009). Isso se evidencia por meio do acesso livre à produção científica, disponível nos repositórios de acesso aberto. Os repositórios podem disponibilizar inúmeros tipos de documentos. Em se tratando dos institucionais, podem apresentar trabalhos de pesquisa e de comunidades acadêmicas e uma variedade de documentos das atividades desenvolvidas nas universidades (Viana et al., 2006).

Os arquivos que compõem os repositórios institucionais, conforme McLendon (2005), podem ser artigos de periódicos peer-reviewed, material pedagógico, material 
de pesquisa, artigos de eventos, teses, dissertações e fotografias. Caribé (2008) afirma que os repositórios institucionais podem disponibilizar pastas eletrônicas dos estudantes, relatórios anuais da instituição, vídeos, programas de computador e qualquer material que a instituição deseje armazenar. A variedade do tipo de documento disponibilizado mostra que os repositórios servem para armazenar o acervo digital de uma instituição, protegendo-o contra eventuais perdas e disponibilizando-o para consulta.

Os repositórios institucionais são importantes, uma vez que atuam como instrumentos de divulgação do conhecimento. O livre acesso aos seus arquivos permite a troca de informações entre os pesquisadores o que acarreta maior impacto nas pesquisas.

\section{Recomendações técnicas para repositório para surdos}

A Norma International Organization for Standardization (ISO) 9241-20 tem o objetivo de ajudar os desenvolvedores na elaboração de TIC que possam ser utilizadas pelo maior número de indivíduos, independentemente de condição física, limitação ou cultura. Conforme essa norma, a acessibilidade subentende atender um amplo grupo de usuários, como pessoas com deficiências físicas, sensoriais e cognitivas; idosos, pessoas com deficiências temporárias e que experimentam dificuldades em situações particulares (International Organization for Standardization, 2008a).

As tecnologias assistivas para surdos e indivíduos com problemas de fala são recursos que facilitam a inclusão digital dessas pessoas. As principais tecnologias assistivas que atendem às especificidades dos surdos são as legendas, amplificadores de volume e aparelhos de audição, sintetizadores de voz e equipamentos que melhoram a qualidade do som. O uso dessas tecnologias facilita a interação dos usuários surdos com a interface gráfica dos sistemas de comunicação.

A partir dos recursos visuais, conforme a ISO 9241-20, a informação verbal, que é a informação textual apresentada em áudio, necessita ser disponibilizada visualmente aos usuários por meio de legenda em texto escrito e/ou em língua de sinais e deve estar sincronizada com a apresentação da informação em áudio (International Organization for Standardization, 2008a).
A norma também recomenda que o uso da língua de sinais nos ambientes digitais deva considerar as variações regionais, nacionais e linguísticas. Cada país tem sua língua de sinais com diferenças nos sinais e na estrutura da língua. Conforme Gesser (2009, p.13),"A língua dos surdos não pode ser universal, pois não funciona como um decalque ou rótulo que possa ser colado e utilizado por todos os surdos de todas as sociedades sendo uniformemente utilizada e não sofrendo influências de outras línguas". As línguas de sinais sofrem influência em sua estrutura, assim como as línguas orais também apresentam diferenças em cada país.

A ISO 9241-20 ressalta a necessidade dos alarmes sonoros serem disponibilizados em versões tácteis, como alertas vibratórios de celulares, com isso o surdo identifica o alerta sonoro por meio da vibração e a possibilidade do controle do volume das informações apresentadas em áudio em ambiente digital. Esse recurso atende aos usuários que apresentam uma perda parcial de audição. Quando é utilizada a entrada de voz para ativar o equipamento, devem ser oferecidas outras alternativas, como os teclados ou o uso de vídeos que monitoram os gestos (International Organization for Standardization, 2008a). A norma também adverte para o apoio às diferenças culturais e linguísticas. A diferença linguística dos surdos é evidenciada pelo uso da língua de sinais.

As recomendações apresentadas na Norma ISO 9241-151 são aplicadas especialmente para o projeto de conteúdo de um site, navegação e interação com os usuários e na apresentação de conteúdo na Web. Essa norma apresenta orientações relacionadas às interfaces na Web, com a finalidade de tornar o ambiente mais acessível (International Organization for Standardization, 2008b).

As recomendações técnicas da norma indicam que o conteúdo disponibilizado na página da Web deve atender as necessidades específicas do seu público-alvo. Considerando como usuários principais do ambiente os sujeitos surdos, é necessário que sejam disponibilizados conteúdos e informações de interesse da comunidade surda. Segundo a ISO 9241-151, os conteúdos podem ser apresentados em forma de textos, imagens, animações ou outros tipos de mídias e podem ser interativos ou não, permitindo o uso de aplicativos da Web pelo usuário. A norma também recomenda disponibilizar equivalentes 
textuais para objetos de mídias não textuais, representados por imagens gráficas ou vídeos (International Organization for Standardization, 2008b).

Os objetos de mídia que são apresentados por meio de vídeo devem disponibilizar a opção de pausar ou parar a apresentação da mídia. O controle do tempo de reprodução desses objetos permite ao usuário acessar um determinado conteúdo que não tenha sido assimilado.

A estrutura de navegação realizada pelos usuários de um ambiente na Internet, conforme a ISO 9241-151, delimita o caminho seguido pelo usuário na interface para obter uma determinada informação. É necessário que a homepage forneça o acesso direto às informações mais importantes ou às que o usuário utiliza com maior frequência, e para isso é importante manter a visibilidade dos links de navegação e o fornecimento do mapa do site, que permite uma visão geral da sua estrutura (International Organization for Standardization, 2008b).

A compreensão pelo usuário do conteúdo do website ocorre de forma rápida, conforme a ISO 9241-151, quando o texto inicia com uma breve conclusão ou síntese do que for posteriormente informado e com resumos com linguagem de fácil entendimento. É útil aos usuários a alternação entre idiomas diferentes em mais de um ponto do website (International Organization for Standardization, 2008b).

\section{Métodos}

A definição do tipo de pesquisa envolve primeiramente identificar os elementos que a caracterizam como de natureza científica. Do ponto de vista dos objetivos, trata-se de uma pesquisa exploratória, pois tem como principal objetivo desenvolver, esclarecer e modificar conceitos e ideias, tendo como base a concepção de problemas mais precisos (Markoni; Lakatos, 2003; Gil, 2008).

Esta pesquisa é caracterizada como descritiva e quali-quantitativa, auxilia a compreensão do objeto de estudo e sua construção a partir de novas abordagens, e revela indicadores e tendências observáveis.

Foi aplicado um questionário formado por 16 questões fechadas e uma questão aberta com os alunos surdos e ouvintes do curso Letras Libras/EaD-UFSC. O questionário foi elaborado com base no modelo de análise de ambientes informacionais proposto por Corradi (2007) por representar uma metodologia de análise já testada em ambientes digitais para surdos. Gil (2008, p.121) define o questionário como uma"Técnica de investigação formada por um conjunto de questões submetidas a pessoas com o objetivo de obter informações sobre conhecimentos, crenças, sentimentos e expectativas, entre outros".

As questões fechadas foram elaboradas com o uso de escala Likert, com o propósito de identificar a manifestação dos sujeitos da pesquisa. A análise das questões foi realizada por meio de estatística descritiva, que "Permite organizar, resumir e apresentar os dados, de tal forma que possam ser interpretados à luz dos objetivos da pesquisa" (Barbetta, 2006, p.65).

Os resultados da questão aberta foram analisados por meio das técnicas de análise de conteúdo. A intenção da análise consiste na inferência de conhecimentos relativos às condições de produção. A partir dessa abordagem, é possível realizar deduções lógicas e justificadas em relação à origem das mensagens (Bardin, 2004). A aplicação da análise de conteúdo possibilitou definir as categorias e subcategorias, tornando evidentes as respostas dos alunos.

A população de uma pesquisa, de acordo com Gil (2008, p.89), "É um conjunto definido de elementos que apresentam certas características". Uma parte do conjunto de elementos corresponde a uma amostra. Foi definida como população da pesquisa os alunos do curso Letras Libras, na modalidade a distância, da Universidade Federal de Santa Catarina. O curso Letras Libras-UFSC forma tradutores-intérpretes em Libras e professores para o ensino de Libras.

A seleção da amostra foi realizada por métodos não aleatórios e por conveniência. Em geral, as técnicas de amostragens não aleatórias procuram gerar amostras que, de alguma maneira, tentem representar razoavelmente bem a população e o local de onde foram extraídas (Barbetta, 2006). Por razões operacionais, foi necessário delimitar como amostra da pesquisa os alunos que estudam nos polos localizados na Região Sul do Brasil, formados pela Universidade Federal de Santa Catarina (UFSC), Universidade Federal do Rio Grande do Sul (UFRGS) e Universidade Federal do Paraná (UFPR). A amostra é 
formada por 159 alunos surdos e ouvintes do Curso Letras Libras/EaD-UFSC dos polos localizados na UFPR, UFSC e UFRGS, sendo 80 alunos da licenciatura e 79 do bacharelado. Vale ressaltar que a licenciatura forma profissionais surdos e ouvintes para atuarem no ensino de Libras e o bacharelado forma profissionais ouvintes para atuarem como intérpretes do Português/Libras e Libras/Português.

Os procedimentos metodológicos aplicados na pesquisa foram aprovados no Comitê de Ética em Pesquisa com Seres Humanos (CEPSH), da Universidade Federal de Santa Catarina (UFSC), no dia 28 de junho de 2010, processo no 852.

Ao todo, 98 alunos do curso de Letras Libras/EaD-UFSC dos polos localizados na UFPR, UFSC e UFRGS responderam ao questionário, sendo 60 alunos da licenciatura e 38 do bacharelado, o que corresponde a 61,63\% da amostra da pesquisa formada pelos alunos dos polos localizados na Região Sul do Brasil. A amostra apresenta 49 alunos surdos e 49 ouvintes. O pesquisador deslocou-se até os polos localizados na UFSC (Florianópolis), UFRGS (Porto Alegre) e UFPR (Curitiba) para a aplicação do questionário e contou com o auxílio de um intérprete em língua de sinais.

\section{Resultados e Discussão}

A partir dos dados obtidos por meio do questionário, foi possível analisar os resultados de acordo com os objetivos propostos. A identificação do perfil constitui a primeira parte e usa estatística descritiva; posteriormente, é feita a discussão sobre o uso da tecnologia, também com estatística descritiva, e, finalmente, a demanda por documentos e tipos de fontes de informação que devem estar no acervo do repositório, por meio de análise de conteúdo da questão aberta.

\section{Perfil dos alunos}

Dos alunos surdos e ouvintes que formaram a amostra da pesquisa, 59,18\% são do sexo feminino; em relação ao estado civil, 51,02\% dos estudantes são solteiros, e em relação à idade, a maioria está nas faixas etárias entre 21 e 30 anos e entre 31 e 40 anos, o que corresponde, respectivamente, a 50,00\% e 35,71\% do número total de alunos dos polos de ensino pesquisados.
Em relação ao idioma, a Libras é apontada pelos alunos surdos e ouvintes como o idioma mais utilizado (57,14\%), seguida pela Língua Portuguesa (53,06\%) e pelo Inglês (20,40\%). Um dos critérios para seleção no curso Letras Libras da UFSC nas modalidades de bacharelado e licenciatura é o conhecimento da Língua Brasileira de Sinais. A Língua Portuguesa é apontada como o segundo idioma mais utilizado. A Língua de Sinais Americana (ASL) é indicada por 5,10\% dos respondentes como a segunda língua de sinais mais utilizada pelos alunos.

No que se refere às modalidades do curso Letras Libras/EaD-UFSC, 61,22\% dos alunos cursam licenciatura e 38,78\% bacharelado. A distribuição dos alunos por atividade remunerada demonstra que $55,93 \%$ dos alunos surdos e 43,59\% dos ouvintes trabalham com carga horária entre 31 e 40 horas semanais. Apenas 10,17\% dos alunos surdos não trabalham e todos os alunos ouvintes desempenham algum tipo de função remunerada, mesmo com carga horária reduzida.

A identificação da percepção dos estudantes sobre a importância dos tipos de escrita indica os recursos necessários para o diálogo no cenário digital em cada uma das alternativas, uma vez que cada uma apresenta requisitos próprios. A Tabela 1 apresenta os resultados dos percentuais do tipo de escrita mais utilizado pelos alunos surdos e ouvintes dos polos do curso Letras Libras localizados na UFSC, na UFRGS e na UFPR.

A Língua Portuguesa é considerada muito importante por 58,33\% dos alunos surdos e 100,00\% dos alunos ouvintes do polo da UFSC; por 72,72\% dos alunos surdos e 100,00\% dos ouvintes do polo da UFRGS e 50,00\% dos alunos surdos e $85,71 \%$ dos alunos ouvintes do polo da UFPR. A perspectiva bilingue na educação expressa o uso de duas línguas para a formação do indivíduo, considerando os aspectos inerentes de cada uma. A Língua Portuguesa na sua forma escrita é considerada importante por representar uma forma de comunicação com a sociedade ouvinte. O sistema de escrita da língua de sinais, que permite a comunicação entre o grupo surdo, ainda está em processo de consolidação.

Há o predomínio, entre os alunos surdos e ouvintes que estudam no curso Letras Libras na modalidade a distância, de pessoas do sexo feminino, solteiros, entre 31 a 40 anos, que se comunicam em Libras, trabalham e utilizam a escrita em português. 
Tabela 1. Tipos de escrita mais utilizados pelos alunos.

\begin{tabular}{|c|c|c|c|c|c|c|c|c|c|c|c|}
\hline \multirow{2}{*}{\multicolumn{3}{|c|}{ Forma de escrita preferida e audição }} & \multirow{2}{*}{$\mathrm{N}$} & \multicolumn{2}{|c|}{ Muito importante } & \multicolumn{2}{|c|}{ Importante } & \multicolumn{2}{|c|}{ Pouco importante } & \multicolumn{2}{|c|}{ Nada importante } \\
\hline & & & & $f$ & $\%$ & f & $\%$ & f & $\%$ & f & $\%$ \\
\hline \multirow{6}{*}{ Surdo } & Escrita em & UFSC & 24 & 14 & 58,33 & 6 & 25,00 & 3 & 12,50 & 0 & 0 \\
\hline & Língua Portuguesa & UFRGS & 11 & 8 & 72,72 & 5 & 45,45 & 0 & 0 & 0 & 0 \\
\hline & & UFPR & 24 & 12 & 50,00 & 12 & 50,00 & 1 & 04,17 & 0 & 0 \\
\hline & Escrita em & UFSC & 24 & 5 & 20,83 & 4 & 16,70 & 6 & 25,00 & 10 & 41,67 \\
\hline & SignWriting & UFRGS & 11 & 0 & 0 & 3 & 27,28 & 6 & 54,55 & 2 & 18,18 \\
\hline & & UFPR & 24 & 1 & 4,17 & 8 & 33,30 & 6 & 25,00 & 8 & 33,34 \\
\hline \multirow{6}{*}{ Ouvinte } & Escrita em & UFSC & 13 & 13 & 100,00 & 0 & 0 & 0 & 0 & 0 & 0 \\
\hline & Língua Portuguesa & UFRGS & 12 & 12 & 100,00 & 0 & 0 & 0 & 0 & 0 & 0 \\
\hline & & UFPR & 14 & 12 & 85,71 & 1 & 7,14 & 0 & 0 & 0 & 0 \\
\hline & Escrita em & UFSC & 13 & 0 & 0 & 0 & 0 & 6 & 46,15 & 5 & 38,46 \\
\hline & SignWriting & UFRGS & 12 & 0 & 0 & 1 & 8,33 & 7 & 58,33 & 3 & 25,00 \\
\hline & & UFPR & 14 & 2 & 14,28 & 2 & 14,30 & 6 & 42,85 & 1 & 7,14 \\
\hline
\end{tabular}

Fonte: Dados da pesquisa.

N: é o número de estudantes da amostra; fé a frequência das respostas.

UFSC: Universidade Federal de Santa Catarina; UFRGS: Universidade Federal do Rio Grande do Sul; UFPR: Universidade Federal do Paraná.

\section{O uso das tecnologias da informação}

A Internet representa para o surdo um meio de acesso à informação e um espaço no qual os indivíduos podem interagir com o uso de recursos visuais a distância, permitindo o desenvolvimento e a formação de conhecimento dos surdos."A tecnologia pode ser utilizada como ferramenta pedagógica de intervenção no processo de comunicação escrita ou visual e interação social dos sujeitos surdos" (Stumpf, 2008, p.18).

A Tabela 2 identifica os requisitos de equipamentos e velocidade de rede utilizados pelos estudantes. A opção por detalhar a questão é saber se a estrutura necessária para a comunicação na língua de sinais é atendida de forma satisfatória.

Verifica-se, nos polos de ensino, a predominância no uso de computadores móveis (37,75\%) e webcam com Internet em velocidade normal (39,79\%) e rápida (26,53\%). Há uma tendência ao uso crescente dos computadores móveis pela sua facilidade no deslocamento e portabilidade. A alta velocidade da Internet requisitada pelos alunos surdos e ouvintes se deve ao uso acentuado de vídeos nas atividades desenvolvidas em sala de aula. A reprodução dos vídeos por meio da Internet com alta velocidade facilita o uso da experiência visual dos surdos, servindo de instrumento pedagógico e de comunicação a partir do qual o surdo consegue interpretar os conteúdos por meio da língua de sinais.
A construção de ambientes digitais para os surdos da educação superior requer a aplicação de critérios de acessibilidade que consideram as especificidades dos surdos. A construção de ambientes digitais acessíveis aos surdos deve considerar o uso de recursos visuais e da língua de sinais para que os surdos tenham acesso à informação e ao conhecimento.

A partir da análise dos resultados dos três polos de ensino em que a pesquisa foi aplicada, percebe-se a predominância de elementos necessários para a construção de um ambiente digital acessível com a presença de vídeos em Libras (88,36\%). Os dicionários digitais $(77,91 \%)$ para a tradução do português para Libras e a presença de conteúdos digitais em formato variado por meio de textos, figuras, ilustrações e vídeos (74,62\%) também são relatados pelos alunos surdos e ouvintes como elementos muito importantes a serem disponibilizados no ambiente digital. A tradução simultânea do português para Libras facilita o entendimento da Libras pelas pessoas surdas e ouvintes que estão aprendendo a língua de sinais. Os dicionários digitais ilustrados disponibilizam uma variedade de sinais que consideram as especificidades das pessoas surdas e são facilmente acessados por meio da Internet.

O emprego de vídeos com legenda em português é uma forma de acesso à informação às pessoas surdas que apresentam pouco conhecimento em Libras e conse- 
Tabela 2. Equipamentos de informática e velocidade da Internet.

\begin{tabular}{|c|c|c|c|c|c|c|c|c|c|c|}
\hline \multirow{2}{*}{ Equipamentos } & & \multirow{2}{*}{ N } & \multicolumn{2}{|c|}{ Lenta } & \multicolumn{2}{|c|}{ Normal } & \multicolumn{2}{|c|}{ Rápida } & \multicolumn{2}{|c|}{ Muito rápida } \\
\hline & & & $f$ & $\%$ & $f$ & $\%$ & $f$ & $\%$ & $f$ & $\%$ \\
\hline \multirow{4}{*}{ Computador fixo } & UFSC & 37 & 2 & 5,40 & 13 & 35,13 & 14 & 37,83 & 3 & 08,10 \\
\hline & UFRGS & 23 & 1 & 4,34 & 6 & 26,08 & 8 & 34,78 & 2 & 8,69 \\
\hline & UFPR & 38 & 2 & 5,26 & 11 & 28,95 & 14 & 36,84 & 3 & 07,89 \\
\hline & Total & 98 & 5 & 5,10 & 30 & 30,61 & 36 & 36,73 & 8 & 8,16 \\
\hline \multirow{3}{*}{ Computador móvel } & UFSC & 37 & 0 & 0 & 13 & 35,13 & 15 & 40,54 & 5 & 13,51 \\
\hline & UFRGS & 23 & 0 & 0 & 10 & 43,47 & 8 & 34,78 & 0 & 0 \\
\hline & UFPR & 38 & 0 & 0 & 12 & 31,57 & 14 & 36,84 & 4 & 10,52 \\
\hline \multirow{5}{*}{ Webcam } & Total & 98 & 0 & 0 & 35 & 35,71 & 37 & 37,75 & 9 & 9,18 \\
\hline & UFSC & 37 & 1 & 2,70 & 13 & 35,13 & 12 & 32,43 & 4 & 10,81 \\
\hline & UFRGS & 23 & 2 & 8,69 & 9 & 39,13 & 4 & 17,39 & 0 & 0 \\
\hline & UFPR & 38 & 3 & 7,89 & 17 & 44,74 & 8 & 21,05 & 2 & 05,26 \\
\hline & Total & 98 & 6 & 6,12 & 39 & 39,79 & 26 & 26,53 & 6 & 6,12 \\
\hline
\end{tabular}

Fonte: Dados da pesquisa.

$\mathrm{N}$ : é o número de estudantes da amostra; fé a frequência das respostas.

UFSC: Universidade Federal de Santa Catarina; UFRGS: Universidade Federal do Rio Grande do Sul; UFPR: Universidade Federal do Paraná.

guem ler por meio da Língua Portuguesa. As legendas em português podem ser utilizadas em ambientes digitais, na Internet e são empregadas na TV, permitindo que o conteúdo apresentado de forma oral seja convertido para o português, que é apresentado em uma tela. A legenda em closed caption permite a tradução literal de tudo o que é apresentado de forma oral nos programas de televisão para a Língua Portuguesa em sua forma escrita. Essa ideia é apresentada na cartilha sobre Acessibilidade do Governo Eletrônico (e-MAG), elaborada pelo governo brasileiro, que tem como propósito tornar os sites e portais governamentais acessíveis à população.

A partir da análise comparativa das respostas obtidas nos três polos de ensino, percebe-se que as ferramentas consideradas mais importantes pelos alunos surdos e ouvintes do curso Letras Libras-EaD são o e-mail (78,54\%), as listas de discussão (54,90\%), o Messenger (52,94\%), as ferramentas para compartilhamento de vídeos, como o YouTube $(48,50 \%)$, e os sites para surdos (48,03\%). Stumpf (2008) afirma que os vídeos, o DVD, as páginas da Internet, os blogs, as comunidades virtuais, o e-mail, os chats, a webcam, a escrita da língua de sinais, o uso do celular com mensagens, os retroprojetores e a TV são recursos que possibilitam a comunicação do surdo e sua interação social.

Os surdos, por meio das listas de discussão e dos telefones celulares, conseguem se comunicar enviando e recebendo mensagens de texto, que muitas vezes substituem a fala, facilitando a comunicação a distância.

As ferramentas para compartilhamento de vídeo, como o YouTube, consideradas muito importantes pelos alunos surdos e ouvintes do Letras Libras, popularizaram-se e com isso os usuários conseguem disponibilizar os vídeos na Internet e compartilhá-los com outras pessoas. O acesso às redes sociais por meio da Internet demonstra que essas ferramentas representam meios que os alunos surdos e ouvintes utilizam para estarem em contato entre si e com os professores do curso. Os repositórios representam um local onde os materiais de ensino e aprendizagem podem ser disponibilizados para serem utilizados pelos alunos em suas atividades acadêmicas.

Isso requer o uso de critérios de acessibilidade, considerando as especificidades dos usuários surdos que utilizam esses ambientes. Um dos requisitos necessários apontados por Corradi e Vidotti (2007) para a construção de um ambiente acessível é o acesso a conteúdos em vários formatos (áudio, língua de sinais e texto), conteúdos em formato hipermídia, links, conteúdos e rótulos em língua de sinais, entre outros.

No que se refere aos softwares, são recursos necessários para os usuários acessarem os ambientes digitais e outras ferramentas tecnológicas. Percebe-se que os softwares com maior demanda pelos alunos surdos e 
ouvintes do curso Letras Libras são Movie Maker (50,05\%), processadores de texto (45,57\%), MSN (45,55\%), Media Player (39,44\%), e planilhas para cálculo (35,40\%).

O uso acentuado dos vídeos pelos professores e alunos em atividades pedagógicas por meio da gravação e edição demonstra o papel educacional dessas mídias no processo de ensino dos surdos, caracterizando a importância dos recursos visoespaciais.

O uso do MSN representa aos alunos do Letras Libras uma estratégia pedagógica por meio da qual eles se conectam e trocam informações sobre as atividades desenvolvidas nas disciplinas e conteúdos trabalhados. Essa ferramenta permite aos alunos surdos um maior estímulo para o uso da Língua Portuguesa em sua forma escrita, permitindo a comunicação com outros alunos surdos e ouvintes.

Os processadores de textos e as planilhas para cálculos também são utilizados com frequência pelos alunos surdos e ouvintes por serem softwares consolidados e requisitados nos ambientes acadêmico e profissional.

Com esses resultados, percebe-se que a Internete suas ferramentas, os softwares e os ambientes digitais que consideram as especificidades dos surdos apresentam relevância para os alunos surdos e ouvintes. O curso funciona na modalidade a distância, e, por meio da Internet, os alunos acessam uma variedade de ferramentas necessárias para desenvolverem as atividades propostas pelos professores. O avanço das TIC devem continuar de forma acelerada, com inovações que tendem a ser incorporadas aos cursos assim que estiverem com um preço acessível aos projetos educacionais e com estrutura confiável (Rodrigues, 2006). As ferramentas tecnológicas representadas pelos softwares, e-mail, listas de discussão, ferramentas para compartilhamento de vídeos, sites para surdos e a forma como a informação é apresentada nos ambientes digitais colaboram para a inclusão digital dos surdos.

A partir da análise das respostas dos três polos, observa-se que os alunos surdos têm preferência pelas videoaulas (67,59\%), dicionários (61,23\%) e apostilas elaboradas por professores $(60,1 \%)$. Os documentos em formato de vídeos, imagens e dicionários são requisitados pelos surdos, pois permitem que a forma de comunicação pre- dominante ocorra por meio da Libras. Faulstich (2007, p.155) afirma que"A iconicidade na Libras é um fenômeno de cognição, visto que uma palavra em Libras é um signo e sua significação ocorre por meio de uma cadeia de interpretantes de diferentes tipos". Afirma também que a iconicidade está relacionada com a forma como o sinal é realizado, considerando seu movimento e configuração da mão, estabelecendo uma relação entre a forma e o ícone.

O uso dos recursos visuais é utilizado pelos surdos como forma de compensar a falta de audição, permitindo a compreensão dos acontecimentos que o cercam e também como meio de comunicação. O uso do dicionário é uma alternativa importante para as pessoas surdas e ouvintes, e a modalidade mais adequada para os surdos, na concepção de Faulstich (2007), é o dicionário por imagem, que põe a entrada visual em primeira ordem e caracteriza-se pelo fato de a imagem representar o próprio verbete.

Os alunos ouvintes dos polos pesquisados consideram mais importantes as videoaulas (86,75\%), os livros $(84,89 \%)$ e as apostilas elaboradas pelos professores (84,37\%). Os alunos ouvintes consideram relevantes documentos em sua forma escrita, influenciados pela cultura ouvinte, que estabelece uma relação entre a fala e a escrita. Esses alunos, ainda que conheçam e utilizem a língua de sinais, têm preferência por documentos em formato tradicional pela aproximação com a Língua Portuguesa como primeira língua.

Percebe-se a preponderância nas respostas dos alunos surdos e ouvintes de que os documentos disponíveis no repositório educacional aberto para surdos devem ser escritos em Língua Portuguesa e com tradução para a língua de sinais ou escritos somente em português.

Os idiomas mais utilizados pelos surdos no Brasil são a Língua Brasileira de Sinais e a Língua Portuguesa, formando uma perspectiva bilíngue, o que também foi comprovado na presente pesquisa: $57,14 \%$ dos alunos surdos e ouvintes informaram apresentar fluência em Libras e 53,06\% em português.

Os requisitos da língua de sinais acrescentam complexidade às estruturas de repositórios necessárias para o uso intensivo de vídeos e opções de tradução de uma língua para outra. 


\section{Documentos do repositório}

Para identificar os documentos que um repositório deve apresentar para atender as demandas da comunidade surda, foi apresentada questão aberta ao final do questionário. A expressão livre dos estudantes foi processada pela técnica de análise de conteúdo, que classifica as manifestações. Para Bardin (2004, p.112), "Classificar elementos em categorias significa investigar o que cada um deles tem em comum com outros".

A partir da análise das respostas, foram identificadas as seguintes categorias: informação, tecnologia, cultura surda e ensino. A categoria "informação", por ser muito genérica e por ter a finalidade de fornecer uma análise mais precisa das respostas obtidas com a questão aberta do questionário, foi dividida nas seguintes subcategorias: assuntos, suporte e acesso. As categorias tecnologia, cultura surda e ensino não apresentam subcategorias. Com o propósito de facilitar a visualização das respostas dos alunos e os termos que deram origem a cada categoria, foi elaborado o Quadro 1, com categorias, subcategorias e a parte das respostas da questão aberta considerada mais importante para a análise. Os termos que apresentaram a maior incidência foram conteúdos em Libras, notícias sobre surdos, dicionário, vídeos, legenda em português, softwares em Libras, livros digitais e artigos.

A par das categorias, subcategorias e dos termos que as originaram, parte-se para a última etapa da análise, que, segundo Valentim (2005, p.132), consiste em"Estabelecer relações entre as categorias e subcategorias e inferências, buscando obter com maior propriedade o entendimento do objeto/fenômeno de estudo".

A categoria "informação" apresentou a maior incidência de termos (81\%) obtidos com análise da questão aberta e foi dividida nas seguintes subcategorias: assunto, suporte e acesso. Em seguida, aparecem as categorias tecnologia (10\%), ensino (6\%) e cultura surda (3\%).

A informação pode ser acessada por meio da tecnologia, e, no caso do curso Letras Libras-EaD/UFSC, ela é essencial para os alunos surdos e ouvintes desenvolverem as atividades solicitadas pelos professores, por meio dos Ambientes Virtuais de Ensino e Aprendizagem (AVEA), das listas de discussão, do e-mail, das videoaulas e das apostilas em formato digital, entre outros.
A categoria "informação" e a subcategoria "assuntos", identificadas com a leitura e a aplicação da análise de conteúdo na questão aberta do questionário, indicam os tipos de informação mais requisitados e assuntos de maior interesse dos alunos e apresentam como termos mais incidentes notícias sobre os surdos, a Língua Brasileira de Sinais e tradução. Pode-se inferir que as notícias sobre os surdos, como atualidades, curiosidades sobre a comunidade surda e outras informações relacionadas com a surdez, são conteúdos relevantes para serem disponibilizados no repositório. Temas relacionados com a Libras e tradução são de interesse dos alunos, pois a Libras é o idioma oficial dos surdos e as traduções Libras/Português ou do Português/Libras são necessárias para o entendimento dos conteúdos. Outros tipos de informação requisitados pelos alunos apresentam como temas saúde, cursos, mercado de trabalho, escrita do português, links para outros sites, termos técnicos e planos de aula.

A categoria"informação" e subcategoria "suporte" se referem aos suportes de informação utilizados pelos alunos. Os tipos de suportes mais indicados são dicionários, vídeos, livros digitais e artigos. Os dicionários da língua de sinais são importantes para os surdos, pois, de acordo com Faulstich (2007), esse tipo de dicionário põe a entrada visual em primeira ordem. Dessa forma, a imagem utilizada no dicionário substitui ou acompanha o próprio verbete. Os vídeos são empregados nas aulas por permitirem a visualização da língua de sinais e a comunicação entre os surdos. Por meio dos vídeos, as aulas de Libras podem ser gravadas e os alunos podem editar as imagens e visualizar os conteúdos. Os livros em formato digital e os artigos são mais facilmente acessados pelo ambiente virtual. Outros tipos de suporte de informação requisitados pelos alunos são DVD, jornais, gramática e glossário.

A categoria "informação" e subcategoria "acesso" se refere à forma como a informação é acessada. O acesso à informação pelos alunos do curso Letras Libras é maior por meio de conteúdos em Libras e legendas em português. Esses critérios de acesso à informação ocorrem principalmente em ambientes digitais, que facilitam o uso desses recursos. As legendas em português também representam uma forma de acesso à informação para as pessoas surdas que apresentam conhecimento na leitura da Língua Portuguesa. A presença do intérprete em Libras 
Quadro 1. Termos de análise de conteúdo.

\begin{tabular}{|c|c|c|c|}
\hline Categoria & Subcategoria & Termos & Frequência de respostas \\
\hline \multirow{24}{*}{ Informação } & \multirow{10}{*}{ Assunto } & Notícias sobre surdos & 8 \\
\hline & & Libras & 2 \\
\hline & & Tradução & 2 \\
\hline & & Saúde & 1 \\
\hline & & Cursos & 1 \\
\hline & & Mercado de trabalho & 1 \\
\hline & & Escrita do português & 1 \\
\hline & & Links para outros sites & 1 \\
\hline & & Termos técnicos & 1 \\
\hline & & Planos de aula & 1 \\
\hline & \multirow{9}{*}{ Suporte } & Dicionário & 6 \\
\hline & & Vídeos & 4 \\
\hline & & Livros digitais & 2 \\
\hline & & Artigos & 2 \\
\hline & & DVD & 1 \\
\hline & & Jornais & 1 \\
\hline & & Gramática & 1 \\
\hline & & Imagens & 1 \\
\hline & & Glossário & 1 \\
\hline & \multirow{5}{*}{ Acesso } & Conteúdo em Libras & 9 \\
\hline & & Legenda em português & 4 \\
\hline & & Intérprete & 1 \\
\hline & & Interatividade & 1 \\
\hline & & SignWriting & 1 \\
\hline \multirow{5}{*}{ Tecnologia } & \multirow{5}{*}{-} & Softwares em Libras & 3 \\
\hline & & Softwares em português & 1 \\
\hline & & Webcam & 1 \\
\hline & & Messenger & 1 \\
\hline & & E-mail & 1 \\
\hline \multirow{4}{*}{ Ensino } & \multirow{4}{*}{-} & Linguística & 1 \\
\hline & & Ensino da cultura surda & 1 \\
\hline & & Aprendizagem do português & 1 \\
\hline & & Interpretação simultânea médico/jurídica & 1 \\
\hline \multirow{2}{*}{ Cultura surda } & \multirow{2}{*}{-} & Espaço cultural & 1 \\
\hline & & Divulgação da comunidade surda & 1 \\
\hline
\end{tabular}

Fonte: Dados da pesquisa.

é considerada pelos alunos um elemento que facilita o acesso à informação pelos surdos.

A categoria "tecnologia" relaciona-se ao uso dos ambientes tecnológicos pelos alunos do curso Letras Libras. Percebe-se a incidência de termos citados pelos alunos relacionados com o uso de softwares em língua de sinais, softwares em português, webcam, Messengere e-mail. O uso da tecnologia tem contribuído para o aperfeiçoamento de pesquisas relacionadas com a língua de sinais.

A categoria "ensino" apresenta como termos citados pelos alunos a linguística, ensino da cultura surda, aprendizagem do português e interpretação simultânea médico-jurídica. "A Libras é reconhecida oficialmente como a língua dos surdos e apresenta em sua estrutura o status linguístico, conferido a ela ainda na década de 1960" (Gesser, 2009, p.29). A linguística, segundo Quadros e Karnopp (2004), é a área que se preocupa com a natureza da linguagem e da comunicação, e, a partir dos estudos linguísticos das línguas de sinais, pode-se observar o entendimento sobre línguas em geral e sobre as línguas de modalidade visuoespacial. Isso demonstra a importância dos estudos linguísticos e da aprendizagem do português como segunda língua para os surdos. O ensino 
da cultura surda também é um termo mencionado pelos alunos.

A categoria "cultura surda" apresenta os seguintes termos citados pelos alunos: o espaço cultural e a divulgação da comunidade surda.

A partir da definição das categorias e subcategorias de análise da questão aberta do questionário foi possível verificar que os documentos mais requisitados pelos alunos surdos e ouvintes do curso a serem disponibilizados em repositório devem estar relacionados com notícias sobre a comunidade surda e língua de sinais. Os tipos de suporte desses documentos que devem estar disponíveis são os dicionários, vídeos, livros digitais e artigos. Há uma demanda dos softwares em língua de sinais e português, webcam, Messenger e e-mail. Os documentos disponíveis no repositório também devem versar sobre linguística, ensino da cultura surda, aprendizagem do português e interpretação simultânea médico-jurídica. Os tipos de documentos a serem disponibilizados no repositório educacional aberto representam uma demanda a ser suprida para atender os alunos do curso Letras Libra. $O$ acesso aos conteúdos deve seguir critérios que facilitem a leitura, a compreensão e a assimilação desses conteúdos, o que torna necessário o uso da língua de sinais; quanto à forma de escrita, são necessários conteúdos escritos em português e com tradução para a língua de sinais, formando perspectiva bilingue. Os repositórios educacionais abertos permitem a ampla difusão de material pedagógico e, ao considerarem as características dos usuários surdos, permitem a ampliação do público e dos tipos de usuários.

\section{Conclusão}

A partir da aplicação do questionário com os alunos surdos e ouvintes do curso Letras Libras-EaD/UFSC, foi possível identificar o perfil, o uso das tecnologias da informação e os tipos de conteúdo que um repositório deve apresentar para atender as necessidades de informação dos alunos surdos e ouvintes do curso.

Em relação ao perfil, os dados da pesquisa apontam que há uma predominância no curso de pessoas do sexo feminino, que estão na faixa etária entre 21 e 30 anos, solteiras, que trabalham com carga horária entre 31 e 40 horas semanais, apresentam fluência em Libras e conhecimento em Língua Portuguesa e Inglês. Em relação à modalidade do curso, verifica-se que 61,22\% dos alunos que compõem a amostra cursam licenciatura e 38,78\%, bacharelado.

No que se refere ao uso das tecnologias da informação e comunicação pelos surdos da educação superior, percebe-se que os alunos surdos e ouvintes do curso Letras Libras-EaD/UFSC utilizam a Internet por ser um recurso necessário para o desenvolvimento de suas atividades acadêmicas principalmente em casa e no ambiente de trabalho.

Em relação ao uso de ambientes digitais pelos surdos, os alunos surdos e ouvintes consideram importante a presença de vídeos em Libras com legendas em português. Os dicionários digitais para a tradução do português para a Libras e a presença de conteúdos digitais em formato variado por meio de textos, figuras, ilustrações e vídeos também são requisitados pelos alunos como elementos importantes a serem disponibilizados no ambiente digital.

As ferramentas da Internet consideradas mais importantes pelos alunos surdos e ouvintes do curso são o e-mail, as listas de discussão, o Messenger, as ferramentas para compartilhamento de vídeos, como o YouTube, e os sites para surdos.

No que diz respeito ao uso de softwares, os alunos surdos e ouvintes utilizam mais os processadores de texto, MSN, Movie Maker, Media Player e planilhas para cálculo. No que se refere aos conteúdos para os alunos surdos, os documentos mais importantes são as videoaulas, os dicionários e as apostilas elaboradas por professores. Os alunos ouvintes dos polos pesquisados consideram como documentos mais importantes as videoaulas, os livros, as apostilas elaboradas por professores. Essa diferença se deve à influência da língua de sinais na formação do aluno surdo, desde sua fase inicial de formação, e da Língua Portuguesa, considerada a primeira língua ou língua-mãe dos alunos ouvintes.

Em relação aos tipos de conteúdos que os alunos surdos e ouvintes gostariam que o repositório disponibilizasse, foram indicadas as notícias sobre surdos, Língua Brasileira de Sinais e tradução; conteúdos com a temática 
sobre tecnologia, considerando o uso de softwares em língua de sinais e Língua Portuguesa; ensino sobre linguística, aprendizagem do português e interpretação médico-jurídica e cultura surda.

Os suportes mais requisitados pelos alunos para que as informações sejam disponibilizadas são os dicionários, vídeos, livros digitais e artigos. Os alunos preferem acessar as informações no repositório por meio de conteúdos em língua de sinais e legendas em português. Os documentos escritos por meio do sistema SignWriting são pouco mencionados.

É necessário o uso da língua de sinais e de legendas em português e conteúdos de interesse da comunidade surda e mídias em formato de texto, imagens e animações. Os repositórios educacionais abertos para surdos contribuem para a educação dos surdos e são instrumentos pedagógicos a serem utilizados e oferecidos pelos professores, facilitando a pesquisa na Internet.

\section{Referências}

ALBAGLI, S. Conhecimento, inclusão social e desenvolvimento local. Inclusão social, v.1, n.2, p.17-22, 2006. Disponível em: <http://revista.ibict.br/inclusao/index.php/inclusao >. Acesso em: 17 fev. 2010.

BARBETTA, P.A. Estatística aplicada as ciências sociais. Florianópolis: UFSC, 2006.

BARDIN, L. Análise de conteúdo. Lisboa: Edições 70, 2004.

BRITO, L.F. Por uma gramática de língua de sinais. Rio de Janeiro: Tempo Brasileiro, 1995.

BUTCHER, N. A basic guide to open educational resources. Vancouver: Commonwealth of Learnig, 2011.

CAFÉ, L. et al. Repositórios institucionais: nova estratégia para publicação científica na rede. In: CONGRESSO BRASILEIRO DE CIÊNCIAS DA COMUNICAÇÃO, 26., 2003, Belo Horizonte. Anais eletrônicos... Belo Horizonte: INTERCOM, 2003. Disponível em: <http://bibliotecas-cruesp.usp.br/3sibd/docs/viana 358.pdf>. Acesso em: 18 maio 2010.

CARIBÉ, R.C.V. A aplicação do desenvolvimento e gerenciamento de coleções na construção de repositórios institucionais. Informação \& Sociedade, v.18, n.2, p.25-40, 2008. Disponível em: $<$ http://www.ies.ufpb.br/ojs2/index.php/ies $>$. Acesso em: 5 jun. 2010.

CORRADI, J.A.M. Ambientes informacionais digitais e usuários surdos: questões de acessibilidade. 2007. Dissertação (Mestrado em Ciência da Informação) - Universidade Estadual Paulista, Marília, 2007.

CORRADI, J.A.M.; VIDOTTI, S.A.B.G. Elementos de acessibilidade em ambientes informacionais digitais: bibliotecas digitais e inclusão social. In: SEMINÁRIO INTERNACIONAL DE BIBLIOTECAS DIGITAIS, 2007, São Paulo. Anais eletrônicos... Campinas: Unicamp, 2007. 1 CD-ROM.

FACHIN, G.R.B.et al. Gestão do conhecimento e a visão cognitiva dos repositórios institucionais. Perspectivas em Ciência da Informação, v.14, n.2, p.220-236, 2009. Disponível em: <http:// portaldeperiodicos.eci.ufmg.br/index.php/pci>. Acesso em: 18 jul. 2010.

FAULSTICH, E. Modalidade oral-auditiva versus modalidade vísuo-espacial sob a perspectiva de dicionários na área da surdez. In: LIMA-SALLES, H.M.M. (Org.). Bilinguismo dos surdos: questões linguísticas e educacionais. Goiânia: Cânone, 2007. p.147-157.

GESSER, A. Libras? Que língua é essa?: crenças e preconceitos em torno da língua de sinais e da realidade surda. São Paulo: Parábola, 2009.

GIL, A.C. Métodos e técnicas de pesquisa social. São Paulo: Atlas, 2008.

INTERNATIONAL ORGANIZATION FOR STANDARDIZATION. ISO 9241-20: ergonomics of human-system interaction accessibility guidelines for information/communication technology (ICT) equipment and services. Geneva: ISO, 2008a.

INTERNATIONAL ORGANIZATION FOR STANDARDIZATION. ISO 9241-151: ergonomics of human-system interaction guidance on world wide web user interfaces. Geneva: ISO, 2008b.

LAASER, W.; RODRIGUES, R.S.; FACHIN, G.R.B. Educação a distância e recursos educacionais abertos. Revista lberoamericana de Educación, v.49, p.1-15, 2009. Disponível em: <http:// www.rieoei.org/index.php>. Acesso em: 7 jun. 2011.

MARCONDES, C.H.; SAYÃO, L.F. Documentos digitais e novas formas de cooperação entre sistemas de informação em C\&T. Ciência da Informação, v.31, n.3, p.42-54, 2002. Disponível em: <http://revista.ibict.br/ciinf/index.php>. Acesso em: 14 jun. 2010.

MARCONI, M.A.; LAKATOS, E.M. Fundamentos de metodologia científica. São Paulo: Atlas, 2003.

MCLENDON, W. Institutional repositories: scholary communications in a digital world. 2005. Available from: <http://www. unc.edu/scholcomdig/whitepapers/mclendon.pdf>. Cited: 5 July 2010.

MORENO, F.P.; LEITE, F.C.L.; ARELLANO, M.A.M. Acesso livre a publicações e repositórios digitais em ciência da informação no Brasil. Perspectivas em Ciência da Informação, v.11, n.1, p.82-94, 2006. Disponível em: <http://portaldeperiodicos.eci. ufmg.br/index.php/pci>. Acesso em: 15 jul. 2010.

ORGANISATION FOR ECONOMIC CO-OPERATION AND DEVELOPMENT. El conocimiento libre y los recursos educativos abiertos. Paris: OCDE, 2008. Available from: <http://www. oecd.org/dataoecd/44/1042281358.pdf>. Cited: 3 May 2011.

QUADROS, R.M.; KARNOPP, L.B. Língua de sinais brasileira: estudos linguísticos. Porto Alegre: Artmed, 2004.

RODRIGUES, R.S. Educação a distância, bibliotecas e informação: integrações possíveis. In: CUNHA, M.V.; SOUZA, F.C. 
(Org.). Comunicação, gestão e profissão: abordagens para o estudo da ciência da informação. Belo Horizonte: Autêntica, 2006. p.33-45.

RODRIGUES, R.S.; TAGA, V.; VIEIRA, E.M.F. Repositórios educacionais: estudos preliminares para a Universidade Aberta do Brasil. Perspectivas em Ciência da Informação, v.16, n.3, p.181-207, 2011. Disponível em: <http://portaldeperiodicos. eci.ufmg.br/index.php/pci>. Acesso em: 8 mar. 2011.

SÁ, N.R.L. Cultura, poder e educação de surdos. Manaus: UFAM, 2002.

SILVA, E.; CAFÉ, L.; CATAPAN, A.H. Os objetos educacionais, os metadados e os repositórios na sociedade da informação. Ciência da Informação, v.39, n.3, p.93-104, 2010. Disponível em: <http://revista.ibict.br/index.php/ciinf>. Acesso em: 4 mar. 2011.

STOKOE, W. Sign language structure: na outline of the visual communication systems of the american deaf. Studies in Linguistics, n.8, p.1-78, 1960.
STUMPF, M. Mudanças estruturais para uma inclusão ética. In: QUADROS, R.M. Estudos surdos III. Petrópolis: Arara Azul, 2008. p.16-31.

TRISKA, R.; CAFÉ, L. Arquivos abertos: subprojeto da biblioteca digital brasileira. Ciência da Informação, v.30, n.3, p.92-96, 2001. Disponível em: <http://revista.ibict.br/ciinf/index.php/ ciinf>. Acesso em: 11 jul. 2010.

VALENTIM, M.L.P. Análise de conteúdo. In: VALENTIM, M.L.P. (Org.). Métodos qualitativos de pesquisa em ciência da informação. São Paulo: Polis, 2005. p.119-134.

VIANA, C.L.M.; ARELLANO, M.Á.M.; SHINTAKU, M. Repositórios institucionais em ciência e tecnologia: uma experiência de customização do DSpace. In: CONSELHO DE REITORES DAS UNIVERSIDADES ESTADUAIS DE SÃO PAULO (Org.). A dimensão social da biblioteca digital na organização e acesso ao conhecimento: aspectos teóricos e práticos. São Paulo: Cruesp, 2006. p.339-365. 
